\title{
Modeling adsorption mechanism of paraquat onto Ayous (Triplochiton scleroxylon) wood sawdust
}

\author{
Fulbert Togue Kamga ${ }^{1}$ D
}

Received: 7 May 2018 / Accepted: 21 November 2018 / Published online: 27 November 2018

(C) The Author(s) 2018

\begin{abstract}
The equilibrium sorption of a local Ayous (Triplochiton scleroxylon) wood sawdust was examined as substitute adsorbent for removal of paraquat from water. Langmuir, Freundlich, Temkin and Dubinin-Radushkevich (DRK) isotherms were used to compare the equilibrium sorption data obtained. The separation factor revealed a constructive sorption experiment since the maximum monolayer coverage $\left(Q_{0}\right)$ from Langmuir isotherm model was found out to be $41.66 \mu \mathrm{mol} / \mathrm{g}$. In addition, the correlation value of Langmuir isotherm model was the maximum among the four adsorption isotherms. From Freundlich isotherm model, the sorption intensity ( $n$ ) that denotes favorable sorption and the correlation value are 2.402 and 0.929 , respectively. Temkin isotherm model was used to calculate the heat of sorption process which corresponds to $18.39 \mathrm{~J} / \mathrm{mol}$, and the mean free energy was estimated from DRK isotherm model to be $0.091 \mathrm{~kJ} / \mathrm{mol}$ which vividly proved that the adsorption experiment was obeyed to a physical process. The results indicate that this local wood sawdust could be employed as an economical material for reducing paraquat from industrial wastewater.
\end{abstract}

Keywords Isotherms $\cdot$ Paraquat $\cdot$ Adsorption $\cdot$ Free energy

\section{Introduction}

In most developed and developing countries, current agricultural and industrial production is based on the use of inputs to overcome the factors limiting the production such as insects, fungi, weeds (Carter 2000). The use of pesticides, which designate substances intended to fight against plant and animal pests, harmful to crops and humans (Worthing 1979), thus makes it possible to optimize yields and ensure significant production and to be viable. The storage, transportation and systematic use of these products are, however, accompanied by significant pollution which is at the root of the destruction of the ecosystem equilibrium. Pesticides are ecologically important due to their high toxicity for living organisms including human beings (Volesky 2001). The toxicological profile of this contaminant is a potential risk for the environment and public health (Bhattacharya et al. 2006; Mishra and Patel 2009). In particular, paraquat or

Fulbert Togue Kamga

kamgafulbert@yahoo.fr

1 Department of Oceanography, Institute of Fisheries and Aquatic Sciences at Yabassi, University of Douala, Box 2701, Douala, Cameroon methylviologene (1,1'-dimethyl-4,4'-bipyridylium) whose formula (Fig. 1) and the physical properties (Table 1) are cationic herbicides that are part of the family of bipyridinium, and whose most common counterpart is diquat (TsungLi et al. 2001).

In commercial formulations, paraquat is in the form of dichloride salt $\left(\mathrm{C}_{12} \mathrm{H}_{14} \mathrm{~N}_{2} \mathrm{Cl}_{2}\right)$ or $\left(\mathrm{C}_{12} \mathrm{H}_{14} \mathrm{~N}_{2}\left(\mathrm{CH}_{3} \mathrm{SO}_{4}\right)^{2}\right)$. These salts are otherwise very soluble in water and almost not in most organic solvents except for methanol. Environmental standards limit the paraquat concentration to $1-3 \mu \mathrm{g} / \mathrm{L}$ for surface water and $0.1 \mu \mathrm{g} / \mathrm{L}$ for drinking water (Akhtar et al. 2007). It presents indeed a great acute toxicity; it is at the origin of the proliferation of free radicals which destroy the cell walls. The depollution of the water of rejection or destined for consumption, and load in paraquat which destroys in human beings many organs and in particular the lungs reveal themselves to be a real wager. It increases the probability to develop Parkinson's illness (Costello et al. 2009; Sartori and Vidrio 2018). Therefore, it is necessary to design feasible processes to minimize the pollution caused by paraquat discharges and to reduce the risks associated with its presence in the environment. Several methods used for the treatment of polluted water in various organic compounds such as photocatalysis using 


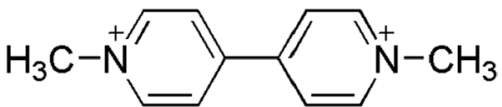

Fig. 1 Chemical structure of paraquat

Table 1 Physical properties of paraquat

\begin{tabular}{ll}
\hline CAS No. & $1910-42-5$ \\
Molecular formula & $\mathrm{C}_{12} \mathrm{H}_{14} \mathrm{C}_{12} \mathrm{~N}_{2}$ \\
Molar mass & $257.16 \mathrm{~g} / \mathrm{mol}$ \\
Density & $1.25 \mathrm{~g} / \mathrm{cm}^{3}$ \\
Fusion point & $175-180^{\circ} \mathrm{C}$ \\
Boiling point & $>300{ }^{\circ} \mathrm{C}$ \\
Solubility in water & $620 \mathrm{~g} / \mathrm{L}$
\end{tabular}

compounds sensitive to UV radiation, the Fenton process which is part of advanced oxidation processes, phytoremediation, reverse osmosis and adsorption which uses various porous matrices to fix and concentrate within them the polluting molecules in solution have been used to decontaminate the water resources of the various pesticides (Lin et al. 2015). Of all these methods, adsorption probably presents the best compromise in terms of processing performance and simple implementation. Due to their high porosity and large surface area $\left(>1000 \mathrm{~m}^{2} / \mathrm{g}\right)$, activated carbons are the most used adsorbents. The search for new adsorbents [clays (Tsai et al. 2003) and zeolites (Erderma et al. 2004)] has allowed us to see that activated carbons could be substituted by other adsorbents, admittedly a little less effective, but much less expensive. It is with this in mind that biosorption uses biomass-based materials as adsorbents. In order to evaluate the feasibility and suitability of natural, viable, renewable and low-cost materials, which will be used as adsorbent to the threat of pesticides, the main objective of this research is to assess the equilibrium sorption data using the notable adsorption isotherms such as Langmuir, Freundlich, Temkin and Dubinin-Radushkevich. Biosorbents, consisting of dead animal and plant biomass (plant, algae, fungi, arthropods, bacteria, yeasts, etc.) with adsorbent properties, are macroporous materials of very large size, giving them specific surface areas rarely exceeding $50 \mathrm{~m}^{2} / \mathrm{g}$ (Do 1998). This limitation is largely compensated by the variety and activity of the functional groups present on their surface (alcohol function, carboxylic function, etc.), which are particularly active for the fixation of a large variety of chemical compounds.

In this work, we will use the sawdust of a local species (Ayous) as biosorbents. The choice of these materials is related to their availability and performance of their counterparts listed in the literature for the biosorption of dyes (Fiset et al. 2000) and heavy metals (Shuklaa et al. 2005).

\section{Experimental methods}

\section{Collection and preparation of adsorbent and adsorbate}

All chemicals used were of analytical grade and were used as received without any further purification. The biosorbent selected for this study is derived from a tropical species found in West and Central Africa. The sawdust used in this work was harvested in a sciuria of the place (carefully avoiding any contamination by sawdust from other species). After drying in the open until constant weight, all the raw materials were crushed and separated into four particle sizes (100-160, 200-300, 300-400 and 400-500 $\mu \mathrm{m}$ ) using sieves of different meshes. The retained size fractions were then thoroughly washed with distilled water and then with methanol (9) and finally rinsed with distilled water, to dissolve the extractables and thus release the pores clogged with them. After 2 days of drying in the open air, the materials are again dried for $2 \mathrm{~h}$ in an oven at $105^{\circ} \mathrm{C}$ and carefully packaged.

\section{Assay of residual paraquat}

The residual paraquat concentration in the filtrates after biosorption was measured by spectrophotometric assay using the strong blue staining of the cation radical (stable in alkaline medium) obtained by paraquat reduction. In practice, a solution of $1.5 \times 10^{-2} \mathrm{M}$ ascorbic acid to reduce the paraquat and $1 \mathrm{M}$ sodium hydroxide to stabilize the blue cation radical formed are introduced into a volume of solution containing paraquat. The absorbance of this solution is measured after $1 \mathrm{~min}$ at a wavelength of $600 \mathrm{~nm}$. Before each set of manipulations, a calibration line is constructed from the stock solution.

\section{Biosorption experiment}

The biosorption of paraquat was carried out by introducing a mass of adsorbent (known particle size) equivalent to $6 \mathrm{~g} / \mathrm{L}$ in a paraquat solution of known concentration. The whole is agitated during a precise duration. After stirring, the supernatants are removed and filtered (filter paper mesh size: phi $0.45 \mu \mathrm{m}$ ), and residual concentrations of paraquat were determined by the analytical method described above.

For the study of the influence of the concentration, masses of $0.15 \mathrm{~g}$ of biosorbent are added to paraquat solutions of $25 \mathrm{~mL}$ volume and concentrations between $5 \times 10^{-5} \mathrm{M}$ and $10^{-3} \mathrm{M}$. The mixtures are stirred for $60 \mathrm{~min}$ at room temperature on a shaking table, then filtered and analyzed using Atomic Absorption Spectrophotometer (2380 UNICAM AAS). In order to interpret the results obtained, the 
adsorption capacity $q_{\mathrm{e}}(\mu \mathrm{m} / \mathrm{g})$ or the percentage of adsorption $T \%$ is determined from the equations below. The amount of adsorbed $(\mu \mathrm{m} / \mathrm{g})$ is calculated using the formulae reported by Vanderborght and Van Grieken (1977):

$q_{\mathrm{e}}=\frac{\left(C_{0}-C_{\mathrm{e}}\right)}{m} \cdot V$

where $C_{0}$ and $C_{\mathrm{e}}$ are, respectively, the initial concentrations and the final concentrations of paraquat, $V$ (in $\mathrm{mL}$ ) the volume of the paraquat solution or the volume of the adsorbate and $m$ (in g) the mass of biosorbent used. $q_{\mathrm{e}}$ is the amount of solute adsorbed from the solution. The data were fitted into the following isotherms: Langmuir, Freundlich, Temkin and Dubinin-Radushkevich (Igwe and Abia 2006). The removal efficiency is determined by computing the percentage sorption using the formula in Eq. (2)

$T=\frac{\left(C_{0}-C_{\mathrm{e}}\right)}{C_{0}} \cdot 100$

\section{Results and discussion}

\section{Sorption isotherms of paraquat}

The equilibrium sorption of the paraquat was carried out by contacting $0.15 \mathrm{~g}$ of the biosorbent with $25 \mathrm{~mL}$ of volume and concentrations between $5 \times 10^{-5} \mathrm{M}$ and $10^{-3} \mathrm{M}$. The mixtures are stirred for $60 \mathrm{~min}$ at room temperature on a stirring table. The mixture was filtered and analyzed for residual concentration after biosorption by spectrophotometer using the strong blue staining of the radical cation obtained by reduction of paraquat. The absorbance of the solution is measured after $1 \mathrm{~min}$ at a wavelength of $600 \mathrm{~nm}$. Langmuir, Freundlich, Temkin and Dubinin-Radushkevich isotherms were used to fit the data. The physicochemical parameters of the Ayous such as the bulk density of the biosorbent are between 0.32 and $0.50\left(\mathrm{~g} / \mathrm{cm}^{3}\right)$, and the particle size $\Phi$ is between 100 and $160 \mu \mathrm{m}$.

\section{Langmuir adsorption isotherm}

Monolayer adsorption occurs at particular homogenous sites on adsorbent. In such case, the Langmuir is usually used. Between the solid and liquid phases (Vermeulan et al. 1966), an equilibrium distribution of adsorbent exists. Langmuir isotherm helps to characterize it. Since a monolayer adsorbate is developed on the outer surface of the adsorbent, Langmuir describes it quantitatively. The formation of the monolayer adsorbate indicates the end of adsorption process. Moreover, Langmuir assumes equal energies of adsorption onto the surface where there is no transmigration of adsorbate in the plane of the surface or in the inner surface of the adsorbent. In the case that surface of adsorbent includes a finite number of identical sites, the Langmuir isotherm is suitable for monolayer adsorption onto it. Based upon these assumptions, Langmuir represented the following equation:

$q_{\mathrm{e}}=\frac{Q_{0} K_{\mathrm{L}} C_{\mathrm{e}}}{1+K_{\mathrm{L}} C_{\mathrm{e}}}$

Langmuir adsorption parameters were found out by transforming the above Langmuir equation into linear form.

$\frac{1}{q_{\mathrm{e}}}=\frac{1}{Q_{0}}+\frac{1}{Q_{0} K_{\mathrm{L}} C_{\mathrm{e}}}$

where $C_{\mathrm{e}}$ is the equilibrium concentration of adsorbate $(\mathrm{mg} / \mathrm{L}), q_{\mathrm{e}}$ is the amount of pesticides adsorbed per gram of the adsorbent at equilibrium (mg/g), $Q_{0}$ is the maximum monolayer coverage capacity $(\mathrm{mg} / \mathrm{g})$ and $K_{\mathrm{L}}$ is the Langmuir isotherm constant $(\mathrm{L} / \mathrm{mg})$. The values of $q_{\max }$ and $K_{\mathrm{L}}$ were calculated from the slope and intercept of the Langmuir plot of $1 / C_{\mathrm{e}}$ versus $1 / q_{\mathrm{e}}$ (Langmuir 1918). The essential features of the Langmuir isotherm can be expressed in terms of equilibrium parameter $R_{\mathrm{L}}$, which is a dimensionless constant referred to as separation factor or equilibrium parameter (Webber and Chakravarti 1974).

$R_{\mathrm{L}}=\frac{1}{\left(1+K_{\mathrm{L}} C_{0}\right)}$

where $C_{0}$ is the initial concentration; $K_{\mathrm{L}}$, the constant related to the energy of adsorption (Langmuir constant).

$R_{\mathrm{L}}$ value denotes the adsorption nature to be either unfavorable if $R_{\mathrm{L}}>1$, linear if $R_{\mathrm{L}}=1$, favorable if $0<R_{\mathrm{L}}$ or irreversible if $R_{\mathrm{L}}=0$. This occurs if $K_{\mathrm{L}}$ is very large, which means that adsorption is too strong. The calculated $R_{\mathrm{L}}$ values as different initial concentrations are shown in Table 2. It was noticed that the value of $R_{\mathrm{L}}$ in the range $0-1$ indicates that Langmuir isotherm is favorable. This is the standard case when adsorption occurs normally, which is not so strong, but noticeably occurs, and we can observe the shape of the adsorption isotherm. Also, lower $R_{\mathrm{L}}$ values at higher initial absorbate concentrations proved that adsorption was more favorable at higher concentration. The degree of favorability is generally associated with the irreversibility of the system, giving a qualitative assessment of the absorbent-absorbate interactions. In the case of the completely ideal irreversible case, the degrees tended toward zero rather than unity which correspond to a completely reversible case.

From this research work, the maximum monolayer coverage capacity $\left(Q_{0}\right)$ from Langmuir isotherm model was determined to be $41.66 \mu \mathrm{mol} / \mathrm{g}, K_{\mathrm{L}}$ (Langmuir isotherm constant) is $0.0124 \mathrm{~L} / \mu \mathrm{mol}, R_{\mathrm{L}}$ (the separation factor) indicates that the equilibrium sorption was favorable and the $R^{2}$ value is 
Table 2 Parameters for plotting Langmuir, Freundlich, Temkin and Dubinin-Radushkevich adsorption isotherms of paraquat onto Ayous sawdust

\begin{tabular}{lclllllllllll}
\hline $\mathrm{S} / \mathrm{no}$. & $C_{0}(\mu \mathrm{mol} / \mathrm{L})$ & $C_{\mathrm{e}}(\mu \mathrm{mol} / \mathrm{L})$ & $1 / C_{\mathrm{e}}(\mu \mathrm{mol} / \mathrm{L})$ & $\log C_{\mathrm{e}}$ & $\operatorname{Ln} C_{\mathrm{e}}$ & $Q_{\mathrm{e}}(\mu \mathrm{mol} / \mathrm{g})$ & $1 / Q_{\mathrm{e}}$ & $\log Q_{\mathrm{e}}$ & $\operatorname{Ln} Q_{\mathrm{e}}$ & $C_{\mathrm{e}} / Q_{\mathrm{e}}(\mathrm{g} / \mathrm{L})$ & $\varepsilon^{2}$ & $R_{\mathrm{L}}$ \\
\hline 1 & 0.00 & 0.00 & 0.00 & 0.00 & 0.00 & 0.00 & 0.00 & 0.00 & 0.00 & 0.00 & 0.00 & 1 \\
2 & 49.91 & 13.91 & 0.0719 & 1.14 & 2.63 & 6 & 0.167 & 0.778 & 1.792 & 2.319 & $29,572.62$ & 0.617 \\
3 & 99.83 & 27.83 & 0.0359 & 1.44 & 3.33 & 12 & 0.083 & 1.079 & 2.485 & 2.319 & 7651.91 & 0.446 \\
4 & 198.92 & 76.52 & 0.0131 & 1.88 & 4.34 & 20.4 & 0.049 & 1.310 & 3.016 & 3.751 & 1034.76 & 0.288 \\
5 & 297.53 & 139.13 & 0.0072 & 2.14 & 4.94 & 26.4 & 0.038 & 1.422 & 3.273 & 5.270 & 314.84 & 0.213 \\
6 & 395.41 & 222.61 & 0.0045 & 2.35 & 5.41 & 28.8 & 0.035 & 1.459 & 3.360 & 7.729 & 123.32 & 0.169 \\
7 & 500.00 & 320.00 & 0.0031 & 2.51 & 5.77 & 30 & 0.033 & 1.477 & 3.401 & 10.667 & 59.76 & 0.138 \\
8 & 605.08 & 403.48 & 0.0025 & 2.61 & 6.00 & 33.6 & 0.030 & 1.526 & 3.515 & 12.008 & 37.61 & 0.117 \\
9 & 695.76 & 486.96 & 0.0021 & 2.69 & 6.19 & 34.8 & 0.029 & 1.542 & 3.550 & 13.993 & 25.83 & 0.103 \\
10 & 800.83 & 570.43 & 0.0018 & 2.76 & 6.35 & 38.4 & 0.026 & 1.584 & 3.648 & 14.855 & 18.83 & 0.091 \\
11 & 901.58 & 674.78 & 0.0015 & 2.83 & 6.51 & 37.8 & 0.026 & 1.577 & 3.632 & 17.851 & 13.46 & 0.082 \\
12 & 995.37 & 772.17 & 0.0013 & 2.89 & 6.65 & 37.2 & 0.027 & 1.571 & 3.616 & 20.757 & 10.28 & 0.074 \\
\hline
\end{tabular}

0.99 (Fig. 2), proving that the sorption data were fitted well to Langmuir isotherm model (Table 2).

\section{Freundlich adsorption isotherm}

The Freundlich isotherm model assumes that the removal of absorbent occurs on a heterogeneous adsorbent surface and can be applied to multilayer adsorption. This is usually applied to explain the adsorption characteristics for the heterogeneous surface (Chaleshtori et al. 2017). Adsorbed molecules react with each other. These data regularly fit the empirical equation suggested by Freundlich:

$Q_{\mathrm{e}}=K_{\mathrm{f}} C_{\mathrm{e}}^{\frac{1}{n}}$

where $K_{\mathrm{f}}$ is the Freundlich isotherm constant (mg/g), $n$ is the adsorption intensity, $C_{\mathrm{e}}$ is the equilibrium concentration of adsorbate $(\mathrm{mg} / \mathrm{L}), Q_{\mathrm{e}}$ is the quantity of pesticides adsorbed per gram of the adsorbent at equilibrium $(\mathrm{mg} / \mathrm{g})$. The adsorption capacity depends on the value of the constant $K_{\mathrm{f}}$ in the adsorption process, while the strength of adsorption is a function of $1 / n$ (Voudrias et al. 2002). $1 / n$ is a heterogeneity parameter; the smaller the $1 / n$, the greater the expected heterogeneity. The concentration is not associated with the subset between the two phases when $1 / n=1$. This expression reduces to a linear adsorption isotherm. Normal adsorption occurs when the value of $1 / n$ is below one. Cooperative adsorption arises in the case $1 / n$ being above one (Mohan and Karthikeyan 1997). If $n$ lies between one and ten, this specifies a favorable sorption process (Goldberg 2005). An asymptotic maximum of the function is observed as the pressure increases. Higher pressures are involved to saturate the surface. The amount of adsorbed ascends more slowly and the constants $K_{\mathrm{f}}$ and $n$ vary to reflect the empirical observation as the temperature increases. However, the sorbent-sorbate system is characterized by two parameters $K_{\mathrm{f}}$ and $n$, respectively. Those parameters must be found out by data fitting. Generally, the parameters of kinetic and isotherm models are usually found through linear regression. Specifically, the linearly transformed equations and the linear least-squares method have been usually used to correlate the sorption data. Linearizing Eq. 7, we have:

$\log Q_{\mathrm{e}}=\log K_{\mathrm{f}}+1 / n \log C_{\mathrm{e}}$

From the data in Table 3 , that value of $1 / n=0.4162$ where $n=2.402$, indicating that the sorption of paraquat onto Ayous sawdust is positive and the $R^{2}$ value is 0.9294 (Fig. 3).

Table 3 Langmuir, Freundlich, Temkin and Dubinin-Radushkevich isotherm constants for the adsorption of paraquat onto Ayous sawdust

\begin{tabular}{|c|c|c|c|c|c|c|c|c|}
\hline \multirow[t]{2}{*}{ Absorbent } & \multicolumn{4}{|c|}{ Langmuir isotherm } & \multicolumn{4}{|c|}{ Freundlich isotherm } \\
\hline & $Q_{0}(\mu \mathrm{mol} / \mathrm{g})$ & $K_{\mathrm{L}}(\mathrm{L} / \mu \mathrm{mol})$ & $R_{\mathrm{L}}$ & $R^{2}$ & $1 / n$ & $n$ & $K_{\mathrm{f}}(\mu \mathrm{mol} / \mathrm{g})$ & $R^{2}$ \\
\hline \multirow[t]{4}{*}{ Ayous } & 41.66 & 0.0124 & $0.074<R_{\mathrm{L}}<1$ & 0.99 & 0.4162 & $n=2.402$ & 3.56 & 0.9294 \\
\hline & \multicolumn{4}{|c|}{ Temkin isotherm } & \multicolumn{4}{|c|}{ Dubinin-Radushkevich isotherm } \\
\hline & $A_{\mathrm{T}}(\mathrm{L} / \mu \mathrm{mol})$ & $b_{\mathrm{T}}$ & $B_{\mathrm{T}}$ & $R^{2}$ & $q_{\mathrm{s}}(\mu \mathrm{mol} / \mathrm{g})$ & $K_{\mathrm{ad}}\left(\mathrm{mol}^{2} / \mathrm{J}^{2}\right)$ & $E(\mathrm{~kJ} / \mathrm{mol})$ & $R^{2}$ \\
\hline & 0.455 & 134.65 & 18.399 & 0.989 & 30.52 & $6 \times 10^{-5}$ & 0.091 & 0.8381 \\
\hline
\end{tabular}




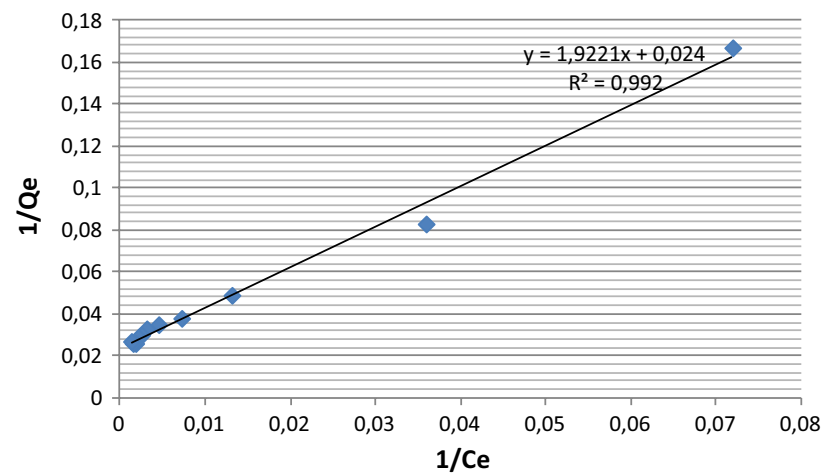

Fig. 2 Langmuir adsorption isotherm

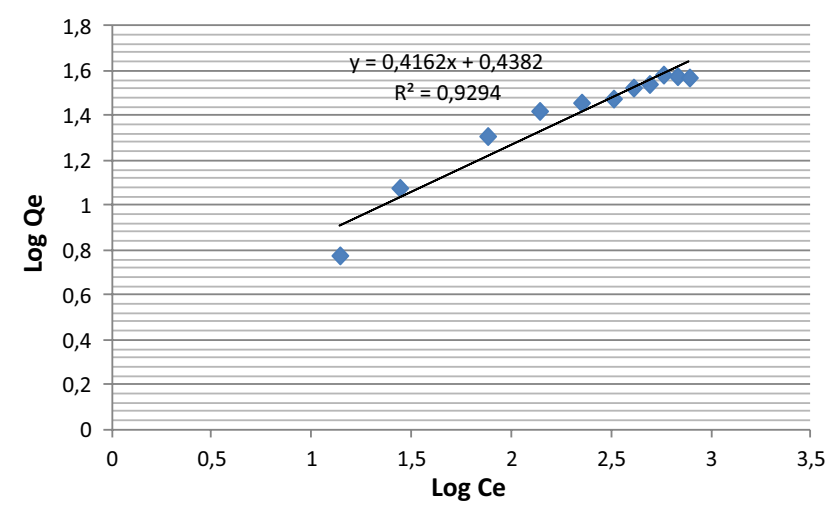

Fig. 3 Freundlich adsorption isotherm

\section{The Temkin isotherm}

This isotherm contains a factor that explicitly takes into the account of adsorbent-adsorbate interactions. It assumes a linear variation of the adsorption heat with the degree of overlap. This equation formulated in the case of the adsorption of gases on solids and transported to the liquid phase, and is one of the only ones giving access to the variation of the adsorption energy which characterizes the way in which the pollutant molecules are retained on the surface of the adsorbent (Ofarmaja 2008). This isotherm is rationally applied for an intermediate range of concentrations. Since the heat of adsorption is function of the temperature of all molecules in the layer, the model assumes that it would not decrease logarithmically but linearly with coverage (Tempkin and Pyzhev 1940; Aharoni and Ungarish 1977). As implied in the equation, its derivation is characterized by a uniform distribution of binding energies. The constants were determined from the slope and intercept by plotting the quantity sorbed $q_{\mathrm{e}}$ against $\ln C_{\mathrm{e}}$. The model is given by the following Eq. 8:

$q_{\mathrm{e}}=\frac{R T}{b_{\mathrm{T}}} \ln \left(A_{\mathrm{T}} C_{\mathrm{e}}\right)$
$q_{\mathrm{e}}=B_{\mathrm{T}} \ln \left(A_{\mathrm{T}}\right)+B_{\mathrm{T}} \ln \left(C_{\mathrm{e}}\right)$

where

$B_{\mathrm{T}}=\frac{R T}{b_{\mathrm{T}}}$

$A_{\mathrm{T}}$ is Temkin isotherm equilibrium binding constant $(\mathrm{L} / \mathrm{g})$; $b_{\mathrm{T}}$, Temkin isotherm constant; $R$, universal gas constant $(8.314 \mathrm{~J} / \mathrm{mol} / \mathrm{K}) ; T$, temperature at $298 \mathrm{~K} ; B$, constant related to the heat of sorption $(\mathrm{J} / \mathrm{mol})$.

From the Temkin plot shown in Fig. 4, the following values were estimated: $A_{\mathrm{T}}=0.455 \mathrm{~L} / \mu \mathrm{mol}, B=18.399 \mathrm{~J} / \mathrm{mol}$, which is an indication of the heat of sorption indicating a physical adsorption process and the $R^{2}=0.989$.

\section{Dubinin-Radushkevich isotherm model}

The apparent energy of absorbent adsorption onto Ayous is found out by using Dubinin-Radushkevich isotherm. Gaussian energy distribution onto a heterogeneous surface (Gunay et al. 2007) is usually used to express the adsorption mechanism by applying the model. It has often successfully fitted into the intermediate range of concentrations data properly and high solute activities.

$q_{\mathrm{e}}=\left(q_{\mathrm{s}}\right) \exp \left(-K_{\mathrm{ad}} \varepsilon^{2}\right)$

$\ln q_{\mathrm{e}}=\ln \left(q_{\mathrm{s}}\right)-\left(K_{\mathrm{ad}} \varepsilon^{2}\right)$

where $q_{\mathrm{e}}$ is the amount of adsorbate in the adsorbent at equilibrium $(\mathrm{mg} / \mathrm{g}) ; q_{\mathrm{s}}$ is the theoretical isotherm saturation capacity $(\mathrm{mg} / \mathrm{g}) ; K_{\mathrm{ad}}$ is the Dubinin-Radushkevich isotherm constant $\left(\mathrm{mol}^{2} / \mathrm{J}^{2}\right)$; and $\varepsilon=$ Dubinin-Radushkevich isotherm constant. As the mean free energy expresses the energy for taking out a molecule from its location in the sorption space to the infinity, the model was usually useful to distinguish the physical and chemical adsorption of pesticides ions with

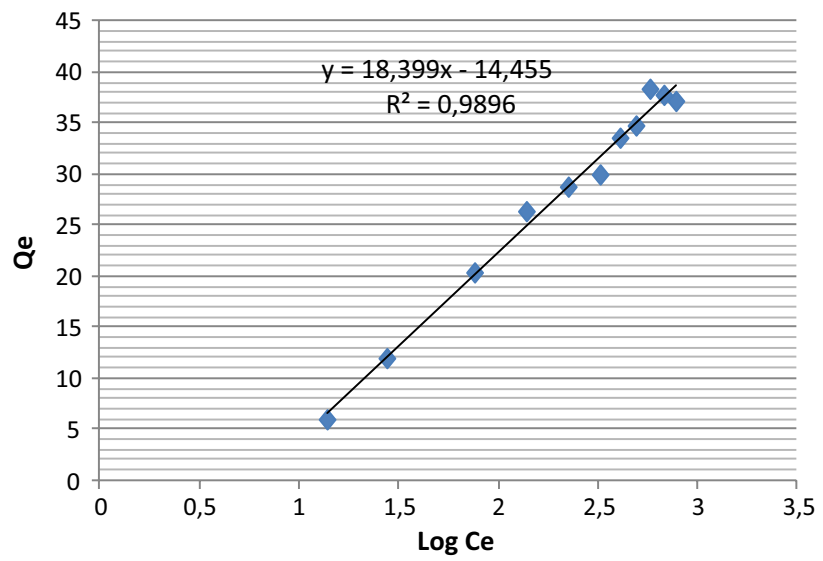

Fig. 4 Temkin adsorption isotherm 


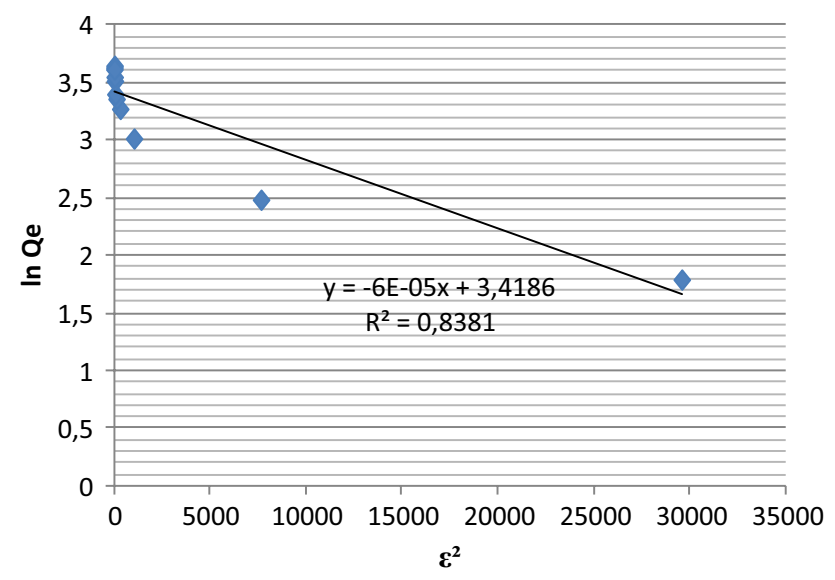

Fig. 5 Dubinin-Radushkevich adsorption isotherm

its mean free energy, $E$ per molecule of adsorbate can be computed by the relationship (Dubinin 1960):

$E=\frac{1}{\sqrt{2 K_{\mathrm{ad}}}}$

The parameter $\varepsilon$ can be calculated as:

$\varepsilon=R T \ln \left(1+\frac{1}{C_{\mathrm{e}}}\right)$

where $R, T$ and $C_{\mathrm{e}}$ characterize the gas constant $(8.314 \mathrm{~J} /$ $\mathrm{mol} / \mathrm{K})$, absolute temperature (K) and adsorbate equilibrium concentration $(\mathrm{mg} / \mathrm{L})$, respectively. Among the models presented above, the Dubinin-Radushkevich (DRK) isotherm model is temperature dependent. When logarithm of amount of adsorbed $\left(\ln q_{\mathrm{e}}\right.$ ) versus $\varepsilon^{2}$ the square of potential energy is plotted as a function adsorption data at different temperatures, it revealed the characteristic curve (Foo and Hameed 2010). Suitable data will lie on that curve. Equation 10 is linearized to Eq. 11 which is applied in the plot of DRK graph in Fig. 5. The constants such as $q_{\mathrm{s}}$ and $K_{\mathrm{ad}}$ were revealed from the appropriate plot using Eq. 11. From the linear plot of DRK model, $q_{\mathrm{s}}$ was determined to be $30.52 \mu \mathrm{mol} / \mathrm{g}$, the mean free energy, $E=0.091 \mathrm{~kJ} / \mathrm{mol}$, demonstrating a physisorption process and the $R^{2}=0.8381$ higher than that of Temkin.

\section{Conclusion}

Four adsorption isotherm models were examined in this research work; investigation of the equilibrium sorption was carried out at $25^{\circ} \mathrm{C}$ and $\mathrm{pH}$ between 6.3 and 6.5. The sorption data were fitted into Langmuir, Freundlich, Temkin and Dubinin-Radushkevich isotherms. The analysis revealed a good correlation between experimental data and Langmuir's isotherm, suggesting a monolayer adsorption on an energetically homogenous surface. Thus, Langmuir adsorption model was found to have the highest regression value and therefore the best fit. It could be concluded that Ayous sawdust is a promise and effective biosorbent for reducing paraquat from aqueous solution and for industrial waste water remediation. The results obtained with Temkin's model confirmed that physical interactions have a prominent role to play in biosorption mechanism of paraquat. The results of this work demonstrated that Ayous sawdust is an effective adsorbent for removal of paraquat from an aqueous solution.

Acknowledgements The author would like to thanks Mr. ENOW William ATEM, assistant lecturer, at University of Douala and anonymous reviewers for suggestions and comments.

Open Access This article is distributed under the terms of the Creative Commons Attribution 4.0 International License (http://creativeco mmons.org/licenses/by/4.0/), which permits unrestricted use, distribution, and reproduction in any medium, provided you give appropriate credit to the original author(s) and the source, provide a link to the Creative Commons license, and indicate if changes were made.

\section{References}

Aharoni C, Ungarish M (1977) Kinetics of activated chemisorption. Part 2. Theoretical models. J Chem Soc Faraday Trans 73:456-464

Akhtar M, Hasany SM, Bhanger MI, Iqbal S (2007) Sorption potential of Moringa oleifera pods for the removal of organic pollutants from aqueous solutions. J Hazard Mater 141:546-556

Bhattacharya AK, Mandal SN, Das SK (2006) Adsorption of Zn(II) from aqueous solution by using different adsorbents. J Chem Eng $123: 43-51$

Carter A (2000) How pesticides get into water and proposed reduction measures. Pestic Outlook 11:149-157

Chaleshtori AAN, Meghadddam FM, Sadeghi MM, Rahimi RR, Hemati S, Ahmadi AA (2017) Removal of Acid Red 18 (AzoDye) from aqueous solution by adsorption onto activated charcoal prepared from almond shell. J Environ Sci Manag 20:9-16

Costello S, Cockburn M, Bronstein J, Zhang X, Ritz B (2009) Parkinson's disease and residential exposure to maneb and paraquat from agricultural applications in the central valley of California. Am J Epidemiol 169:919-926

Do DD (1998) Adsorption analysis, equilibria and kinetics, Series on Chemical Engineering, vol. 2. Imperial College Press, London

Dubinin MM (1960) The potential theory of adsorption of gases and vapors for adsorbents with energetically non-uniform surface. Chem Rev 60:235-266

Erderma E, Karapinar N, Donat R (2004) The removal of heavy metal cations by natural zeolites. J Colloid Interface 280:309-314

Fiset JF, Blais FF, Cheickh RB, Tyagi RD (2000) Review on metal removal from effluents by adsorption on sawdusts and wood barks. Rev Sci Eau 13:325-349

Foo KY, Hameed BH (2010) Insights into the modeling of adsorption isotherm systems. Rev Chem Eng J 156:2-10

Goldberg S (2005) Equations and models describing adsorption processes in soils. Soil Science Society of America, 677 S. Segoe Road, Madison, WI 53711, USA. Chemical Processes in Soils. SSSA Book Series, no. 8 
Gunay A, Arslankaya E, Tosun I (2007) Lead removal from aqueous solution by natural and pretreated clinoptilolite: adsorption equilibrium and kinetics. J Hazard Mater 146:362-371

Igwe JC, Abia AA (2006) A bioseparation process for removing heavy metals from waste water using biosorbents. Afr $\mathbf{J}$ Biotechnol 5:1167-1179

Langmuir I (1918) The adsorption of gases on plane surfaces of glass, mica and platinum. J Am Chem Soc 40:1362-1403

Lin K-YA, Heish Y-T, Tsai T-Y, Huang C-F (2015) TEMPO-oxidized pulp as an efficient and recyclable sorbent to remove paraquat from water. Cellulose 22:3261-3274

Mishra PC, Patel RK (2009) Removal of lead and zinc ions from water by low cost adsorbents. J Hazard Mater 168:319-325

Mohan S, Karthikeyan J (1997) Removal of lignin and tannin color from aqueous solution by adsorption on to activated carbon solution by adsorption on to activated charcoal. Environ Pollut 97:183-187

Ofarmaja AE (2008) Kinetic study and adsorption mechanism of methylene blue and methyl violet onto Mansonia (Mansonia altissima) wood sawdust. Chem Eng J 143:85-95

Sartori F, Vidrio E (2018) Environmental fate and ecotoxicology of paraquat: a California perspective. Toxicol Environ Chem. https ://doi.org/10.1080/02772248.2018.1460369

Shuklaa SS, Yua L, Dorrisa LK, Shuklab A (2005) Removal of nickel from aqueous solutions by sawdust. J Hazard Mater B121:243-246

Tempkin MI, Pyzhev V (1940) Kinetics of ammonia synthesis on promoted iron catalyst. Acta Phys Chim USSR 12:327-356
Tsai WT, Lai CW, Hsien KJ (2003) Effect of particle size of activated clay on the adsorption of paraquat from aqueous solution. J Colloid Interface Sci 263:29-34

Tsung-Li K, Dong-Liang L, Ray HL, Fumio M, Yoshiaki H (2001) Spectra interference between paraquat and diquat by second derivative spectrophotometry. Forensic Sci Int 121:134-139

Vanderborght M, Van Grieken E (1977) Enrichment of trace metals in water by adsorption on activated carbon. Anal Chem 49(2):311-316

Vermeulan TH, Vermeulan KR, Hall LC (1966) Fundamental. Ind Eng Chem 5:212-223

Volesky B (2001) Detoxification of metal-bearing effluents, biosorption for the next century. Hydrometallurgy 59:203-216

Voudrias E, Fytianos F, Bozani E (2002) Sorption description isotherms of dyes from aqueous solutions and waste waters with different sorbent materials. Glob Nest Int J 4:75-83

Webber TN, Chakravarti RK (1974) Pore and solid diffusion models for fixed bed adsorbers. J Am Inst Chem Eng 20:228-238

Worthing CR (1979) The pesticide manual, 6th edn. British Crop Protection Council, Croydon, pp 399-400

Publisher's Note Springer Nature remains neutral with regard to jurisdictional claims in published maps and institutional affiliations. 